\title{
Nurses'Viewpoints on Implementation of Continuing Education Programs at Hospitals
}

\author{
Farideh Malekshahi, ${ }^{1}$ Jafar Rezaian, ${ }^{2}$ Shirzad Fallahi, ${ }^{3}$ Mohammad Almasian ${ }^{4}$
}

\begin{abstract}
Background: Continuing education programs (CEP) are among the most common methods of bringing the medical staff, especially the nurses, up-to-date. Evaluation of the implementation of CEP is needed to optimize such programs and to eliminate any faults. This study aimed to identify the viewpoints of the nurses about CEP in 2015.

Materials \& methods: The study was carried out on all the 750 nurses working in the hospitals of the Lorestan province using the census method. From among these 750 nurses, 537 were included in the study. The data collection instrument was a researcher-designed self-administered questionnaire including demographic information and some questions regarding the necessity of CEP, obstacles to the implementation and the methods of implementation of such programs.

Results: The findings showed that $42.6 \%$ of the participants considered it very important that CEP be implemented. $48.8 \%$ of the participants considered the presentation of educational materials on compact disks (CDs) as the most appropriate method. $53.1 \%$ considered a time interval of once a month in the mornings for the implementation of the CEP as appropriate.

Conclusions: According to results, continuing education plays an important role in nursing, and the continuation of such educational programs as well as improving their quality is highly necessary.

Keywords: Continuing education programs; Implementation; Nurses' Viewpoints; Hospital.

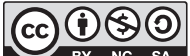

DOI: https://doi.org/I0.3329/jom.v20i2.42007

Copyright: (C) 2019 Malekshahi $F$ et al. This is an open access article published under the Creative Commons Attribution-NonCommercial-NoDerivatives 4.0 International License, which permits use, distribution and reproduction in any medium, provided the original work is properly cited, is not changed in any way and it is not used for commercial purposes.
\end{abstract}

Received: 14 June, 2018;

Accepted: 04 October, 2018

\section{Introduction:}

In today's complex world, learning is of particular importance. Education is the foundation of all learning and its implementation is one of the most important duties of managers in organizations. ${ }^{1,2}$ In fact, the development of human resources is needed in order to promote the competence, to raise the awareness, and to build the skills of employees for better clinical services to be offered. ${ }^{3}$

1. Department of Health Education, Faculty of Nursing and Midwifery, Lorestan University of Medical Sciences, Khorramabad, Iran

2. Department of Anatomy, Faculty of Medicine, Lorestan University of Medical Sciences, Khorramabad, Iran

3. Department of Parasitology and Mycology, Faculty of Medicine, Lorestan University of Medical Sciences, Khorramabad, Iran

4. Instructor, Department of the English Language, Lorestan University of Medical Sciences, Khorramabad, Iran

Corresponding author: Jafar Rezaian, Department of Anatomy, Faculty of Medicine, Lorestan University of Medical Sciences, Khorramabad, Iran. Email: jafarrezaian@gmail.com.
Continuing education is one of the methods of human resource development and is the most important method of experiential training, because, in this method, the employees obtain adequate experience and knowledge during work and become self-made individuals. Additionally, the efficiency of the employees will be increased and the implementation of programs will be successful. ${ }^{4,5}$ In this regard, continuing medical education was officially recognized in 1974 in the world and was proposed as one of the objectives of the medical education and development centers. ${ }^{6}$ In Iran, the 1990 Continuing Education of the Medical Community law was ratified by the Parliament with the aim of promoting the knowledge and work skills of the medical staff and the improvement of health care and treatment services in the country. ${ }^{1,7}$ Now, for more than two decades since its adoption, medical universities have participated in the organization of continuing education programs (CEP). Continuing education is a process that serves to improve and increase the efficiency of the staff in various career opportunities and puts work-related information as needed 
at the disposal of the staff in order to help them achieve organizational goals ${ }^{1-3,7}$ and includes all the activities designed to promote and enhance the competence, knowledge and skills of the staff in order for them to provide better clinical services. ${ }^{8,9}$ Continuing learning is an ongoing need for all nurses. Formal training is just one of the sources of such learning and training. ${ }^{2,10}$ For maximum effectiveness and relevance, CEP should be tailored to the needs of the learners. ${ }^{11}$ In this connection, Shakurnia et al. in a descriptive study titled "Do the content and time of CEP for general practitioners employed in the Khuzestan Province of Iran conform with their expressed needs?", which was conducted on 300 general practitioners showed that the time allotted to most CEP does not correspond with the expressed needs of the physicians and, therefore, they suggest that before designing such programs, needs assessments be conducted in order to enhance the effectiveness of these programs and improve the quality of continuing medical education. ${ }^{6}$

Educational needs assessment is an important tool in the design and evaluation of CEP and can be a positive step towards improving the quality of medical education. ${ }^{11,12}$ The identification and prioritization of needs is the first step in planning. In this regard, the assessment of the implementation of existing programs with the purpose of optimizing the process and removing any possible errors is a requirement for improving the quality of education. ${ }^{2,11-14}$ It is important to examine the implementation of CEP to determine the effectiveness of such programs and their impact on the professional development of nurses. ${ }^{11,14}$ The results of a study by Shirazi et al. titled "The training needs of general surgeons in the CEP of Tehran University of Medical Sciences as viewed by the participants" showed that the majority of the participants consider a duration of less than three days to be useful. ${ }^{14}$ However, continuing education is a means, especially for the nurses, to increase their professional skills as needed. CEP that are based on a detailed needs analysis can be effective and successful. With regard to the circumstances and needs of program participants and their sociocultural conditions, the implementation environment, and the professional characteristics of the individual participants, needs analysis helps with the offering of a continuing education program that fits the needs of each group, and as a result, continuing education will affect the health services provided by health care workers and will reduce the costs and increase the motivation of health. ${ }^{11,14}$ Therefore, the implementation of CEP should be based on the needs of the individuals to increase the efficiency and effectiveness of such education.

\section{Aim of the study}

Given the fact that an official survey of the viewpoints of the nurses has not been previously conducted and analyzed scientifically, this study aims to investigate the viewpoints of nurses employed in the hospitals of the Lorestan Province of Iran regarding the implementation of CEP. Obviously, finding out about the participants' views and applying them in the design of training programs can improve the quality of programs and lead to more satisfaction for the participants.

\section{Materials \& methods: \\ Design and samples}

This was a descriptive / cross-sectional study. The study population included all the nurses (B.Sc., M.Sc.) employed in teaching hospitals, private hospitals, and the Social Security hospitals of the Lorestan Province of Iran. The census sampling method was used.

\section{Instrument}

The data collection instrument was a researcher-designed questionnaire consisting of two parts prepared based on valid information and resources. The first part included 12 closed-ended questions related to personal and demographic characteristics such as age, sex, marital status, educational level, time since graduation, employment status, work history and experience, the work shift in the last 2 years, participation in CEP or workshops and seminars related to their profession, the need for CEP, and 2 open-ended questions about obstacles to CEP. The second part of the questionnaire was related to the implementation of CEP from the perspective of the nurses and had 12 closed-ended questions and two open-ended questions.

\section{Reliability and validity}

To determine the content validity of the questionnaire, the views of 5 faculty members, the director of the Medical Education Development Office, a statistician, the director of the Lorestan Province Nursing Office, 5 clinical nurses, and 5 nursing students were obtained. After making the necessary corrections, the face and content validities of the questionnaire were confirmed. To determine the reliability of the study, the test-retest method was used in a pilot study, such that the questionnaire was sent to 15 individuals from among the participants twice with an interval of one week. The Cronbach's alpha was determined by Pearson correlation coefficient as $80 \%$.

\section{Procedure}

After obtaining the permission of the Lorestan University of Medical Sciences and coordination with the Nursing Office and the Social Security Hospital of the Lorestan Province, 
the number of the nurses holding B.Sc. and M.Sc. degrees was determined. After confirming the validity and reliability of the questionnaire, with the help of matrons and ward supervisors, the questionnaire was put at the disposal of the nurses in different work shifts. The participants were assured that the information would remain confidential and participation in the study was voluntary. The data was collected in one stage using the self-report method. 750 questionnaires were distributed, 671 of which were completed. After examining the questionnaires, some blank and incomplete questionnaires were removed. Finally, 537 questionnaires were determined to be fit for evaluation.

\section{Data analysis}

Descriptive and inferential statistics including frequency, percentage, mean, standard deviation, and the chi-square test were used to analyze the data using the SPSS software version 15 .

\section{Research ethics}

The study was approved by the Ethical Committee at Lorestan University of Medical Sciences. The participants were informed about the study, that their responses would be confidential, and about how to withdraw from the study. Returning the questionnaire was regarded as consent to participate.

\section{Results:}

\section{Study subjects}

The results showed that $30.5 \%$ were in the $30-34$ age group with the mean and standard deviation of $33 \mathrm{y} \pm 6.396 .84 .5 \%$ of the participants were female and $61.1 \%$ were married. The duration of time since graduation was at least 5 months and at most 29.4 years. The mean and standard deviation of work experience was $8.6 \pm 633.520$ years. The majority of the participants (45.8\%) had a formal employment status. $87.5 \%$ of the nurses worked in government hospitals, and $43.6 \%$ worked in Khorramabad, Iran. The majority of the participants $(97.39 \%)$ worked overtime, in addition to their required hours. $87.2 \%$ were clinical nurses and $12.8 \%$ were supervisors (matrons) and 93.5\% had an M.Sc. degree. In terms of work shift, $79.5 \%$ had a rotational shiftwork, $18.6 \%$ worked in the mornings, $0.4 \%$ worked in the afternoons, and $1.5 \%$ worked the night shift.

Table I. Frequency of the impact of training programs previously spent on the quality of scientific and practical activities of nurses

\begin{tabular}{lcccc}
\hline Ineffective & $\begin{array}{c}\text { Less } \\
\text { effective }\end{array}$ & $\begin{array}{c}\text { The average } \\
\text { effective }\end{array}$ & Effective & $\begin{array}{c}\text { Very } \\
\text { effective }\end{array}$ \\
\hline $2.4 \%$ & $7.6 \%$ & $43.4 \%$ & $29.4 \%$ & $15.3 \%$ \\
\hline
\end{tabular}

Table II. The frequency of the necessity of CEP from the viewpoint of the nurses employed in the Lorestan Province.

\begin{tabular}{lcc}
\hline Necessity rate & Frequency & Percent \\
\hline High necessity & 229 & 43 \\
Necessity & 217 & 40.7 \\
Average necessity & 79 & 14.8 \\
Low necessity & 2 & 0.4 \\
No necessity & 6 & 1.1 \\
\hline
\end{tabular}

Nurses' attitudes to participate in training courses

In examining the question of participation in CEP (workshops, seminars, etc.) related to the nursing profession in the past two years, the results indicate that $75.4 \%$ of the participants had participated in CEP to upgrade and enhance their professional knowledge and skills. $96.8 \%$ of the nurses had taken part in a report writing workshop, $90.3 \%$ had participated in a communication with patients' workshop, $91 \%$ had participated in a patient education and training workshop, 78.4\% had taken part in a CCU workshop, $85.8 \%$ had participated in an ICU workshop. The results of the item related to the need for training programs are shown in Table I.

The results of the open-ended question related to the barriers to continuing education of the nurses confirmed that there are a number of obstacles: the large number of work shifts (25.7\%), lack of information regarding the time and the venue of the program $(4.7 \%)$, problems with the time of the training (4.7)\%, lack of cooperation of the directors and managers $(6.7 \%)$, work pressure $(9.7 \%)$, lack of sufficient personnel in the ward $(9.3 \%)$, the creation of pressure on colleagues (6.7) $\%$, and $0.2 \%$ pointed to delays in the registration of the nurses.

Nurses' viewpoints on implementation and obstacles of CEP Regarding the implementation of CEP from the perspective of the participants, $48.6 \%$ preferred CDs and $4.1 \%$ preferred interactive software in the presentation of specialist materials related to their professions. Regarding appropriate time intervals for CEP, $53.1 \%$ preferred these programs to be held once a month, $13 \%$ every two weeks, $11.3 \%$ every two months, and $7.1 \%$ considered intervals of four months or longer as appropriate. About the right time for the training programs, $61.5 \%$ considered only mornings as the appropriate time and $48.4 \%$ preferred the weekends for the CEP. The majority of the participants $(55.7 \%)$ stated that they should be informed at least one month before the implementation of the programs.

Regarding important factors in the development of educational content, $12.7 \%$ mentioned the applicability of the content, $35.1 \%$ mentioned the use of new topics, $2.3 \%$ 
mentioned the consolidation of previously learned content, and $49.9 \%$ mentioned all three as important. $94.5 \%$ of the subjects agreed that participation in training programs should be considered as a work shift. $74.5 \%$ of the nurses said that training programs should be conducted for all nurses regardless of years of service and $78 \%$ wanted such programs to be conducted for all nurses regardless of the type of employment. In response to the question of "How many hours do you consider enough for the implementation of each program?" $58.5 \%$ of the participants said that the time required for training depends on the type of plan. However, $16.9 \%$ considered one day to be enough, $19.2 \%$ considered two days enough, and $5.4 \%$ regarded three days to be sufficient. The results regarding the quality of the educational programs indicated that $36.5 \%$ of the nurses said that previous programs had been at a good level, 50.1\% considered those programs as having an average quality, and $14.4 \%$ evaluated previous programs as having poor quality.

\section{Discussion:}

One of the most important factors in improving the quality of CEP commonly discussed in local and international studies is an emphasis on planning based on the needs, interests, and priorities of the learners. ${ }^{6,15,16}$ So a systematic and comprehensive needs assessment is a prelude and a prerequisite to the successful and satisfying design of CEP. ${ }^{1,6}$ The results of this study showed that nurses considered the necessity of CEP as very high (Table 2). Therefore, it is recommended that nursing managers and directors pay attention to the training and development of nurses as a necessity, and emphasize the proper implementation of these programs. ${ }^{1,10}$ In this study, more than two-thirds of the nurses were female with a mean age of $6.396 \pm 36$, and a mean work experience of $6.520 \pm 63.8$ years, and almost half of the participants had a formal employment status that is consistent with the findings of Jalali et al.

In this study, nurses were very willing to participate in CEP and had shown this willingness by having participated in workshops such as report writing, communication with patients, patient education. Therefore, to increase the motivation of nurses to participate in these programs, barriers can be reduced by adopting methods such as increasing the number of employed nurses, reducing the workload, and assigning special times to continuing education. Despite the positive points of the continuing medical education law, continuing medical education participants in this study evaluated its implementation at a medium level. Therefore, it is recommended that, in addition to the correct application of laws and administrative procedures, ongoing and periodical needs assessment before the training programs, and the re-evaluation and measuring of the effectiveness of programs after their implementations be performed in order to increase the effectiveness of these programs. CEP include seminars, conventions, workshops, conferences, short-term professional courses, codified programs, self-education, training, and research activities. ${ }^{6,16}$ Self-education is a good way of continuing one's medical education that involves individual activities that a person pursues by methods other than personal participation in collective events to improve their scientific and practical knowledge based on personal interest and desire, and includes studying books and periodicals, and using software, websites, and CD's (compact disks). ${ }^{18}$ In this study, about half of the nurses considered presentation of material on CDs as an appropriate method for teaching specialized subjects related to their professions. Older participants (39-35y) significantly $(p \leq 0.025)$ preferred $\mathrm{CDs}$ to other methods of training. This finding of the present study can be explained by the fact that given that CDs are prepared with short, concise, and conceptual information on specific topics for a target audience and can create the possibility of learning at the learner's desired time and place, they can have positive and favorable effects in training different groups. The benefits of PC-based tools, such as $\mathrm{CDs}$, is that utilizing them can reduce the expenses of providing educational content. These tools also allow the easy and cheap storage and transfer of information. ${ }^{19}$ Selflearning is a good way of medical education that is used in many countries..$^{20,21}$ The advantage of self-education practices is the use of leisure time and the selection of the time and place of learning by learners. ${ }^{18}$ It seems that continuing medical education learners prefer self-education due to being busy, having difficulties in leaving the place of service, and other problems. In a survey of general practitioners, pharmacists, and dentists conducted in the Isfahan University of Medical Sciences, the results showed that individuals subject to continuing education laws prefer self-education, ${ }^{18}$ which is in line with the present study. The doctors' preference for self-education could be attributed to their numerous work shifts, which causes them to have less time to participate in CEP. ${ }^{19,20}$ In similar studies in New Orleans and in Dundee Dental School and Phelps, this advantage of self-education, i.e. choosing the time and place of learning by the learner, has also been mentioned. ${ }^{10,11}$ Thus, using self-learning methods in continuing education can provide the opportunity to learn useful content more easily and the use of this method is recommended. Additionally, the results of the present study indicate that, given the willingness of nurses to use CDs, self-learning methods must be of high quality so that the objectives of 
continuing education will be achieved. ${ }^{18}$ Awareness of the views of the audiences of CEP on various aspects of these programs is of particular importance. ${ }^{11,18,21}$ E-learning creates extraordinarily flexible learning opportunities for learners without limitations of time and place, such that learners can learn at any time and any place and at their own pace and also in ways which they prefer to learn. ${ }^{22,10}$ Despite the expansion of educational opportunities available on the Internet, the use of interactive software and online instructional sites in this study was negligible, which is consistent with the results of the study by Ebrahimi Kooshkmahdi and Assadi. In this regard, a study in Germany in 2007 found that although the majority of doctors in the study were computer literate, but their use of internet-based CEP was reported as only $19 \% .^{22,23}$

In the present study, the low level of use of internet sources may be due to unfamiliarity with computers and the Internet, particularly in older and experienced nurses, lack of access to a computer or broadband Internet access at home or at work, failure to provide adequate training, negative attitudes due to lack of necessary equipment and skills, and lack of enough time to use these methods. However, factors such as the presence of equipment, skills, and knowledge in the use of the Internet, and allocation of sufficient time can create a positive attitude towards the Internet and interactive software. Given the low percentages of internet use, this study suggests improving attitudes through education and information dissemination regarding the benefits of these sources and the provision of facilities such as access to the Internet and interactive software. In examining the obstacles to CEP, the results showed nurses pointed to work shifts as a major obstacle in the way of continuing education. In a study titled "An investigation of the viewpoints of the nurses working in Kermanshah, Iran, regarding continuing education", Jalali and colleagues reported work shift as a major obstacle in the implementation of continuing education. In another study $68 \%$ of the participants considered the work shift as an obstacle, $65 \%$ mentioned the time for CEP, $20 \%$ pointed to lack of awareness of the time and venue of programs as the barriers which is consistent with this study. Leifer considers it imperative to raise the awareness of the nurses and prepare them for participation in CEP. ${ }^{24}$ Brady reported high workload and increased work pressure on colleagues at the time of participation in CEP as obstacles to such participation. Better coordination with nurses and nurse managers in hospitals seems necessary for the implementation of CEP. On the other hand, based on the results of the present study, in order to create the possibility of learning from training programs for nurses who work various shifts, so that such learning may interfere less with their work and family duties, the use of non-participatory programs of continuing education is required.

Regarding important factors in the development of educational content, nearly half of the nurses mentioned applicability, having new content, and consolidation of previously learned information as important. The results of a study by Borji et al. titled "The views of general practitioners regarding the contents of continuing medical education programs" in 2004 showed that $87.7 \%$ of the participants called for the presentation of applicable and applied materials. In another study by Vaezi in 2012, consolidation of previously learned materials was the main objective of the participants $(52.6 \%)$, which is consistent with our results. It appears that the information presented in CEP should be up-to-date, since continuing education is implemented to bring the knowledge and skills of health care staff up-to-date. ${ }^{12,26-28}$

In the present study, more than half of the nurses wanted CEP to be held on the weekends, and this is similar to other studies. 6,26,27 Moreover, in a study in 2010, Kousha et al. and general practitioners wanted CEP be held in two to three consecutive days. Similarly, the nurses in the present study wanted training programs to run in two consecutive days. More than half of the nurses considered intervals of once a month and the mornings as appropriate for CEP. ${ }^{13}$. From the viewpoint of the nurses, CEP can be useful when they are held during the weekends and in the mornings. Paying attention to the needs and limitations of nurses can play an important role in attracting their attention. One of the main steps in the proper execution of the continuing education law is to select the duration and time of the programs according to the needs of the medical community, because this increases the participation of the individuals in the design of proper educational programs, increases motivation, and improves the quality of the programs. ${ }^{6}$ In this connection, Ebrahimi Kooshkmahdi and Assadi point out in their study that the shorter the duration of the training, the more welcome it will be. The reason could be that the educational population includes graduates who are busy working and their professional duties do not let them participate in long courses and programs. ${ }^{22}$ Therefore, it is recommended that CEP should be planned based on the views of the participants, and their needs should be considered in the design and implementation stages. In this study, more than half of the nurses evaluated the implementation of CEP to be of average quality that is consistent with the results of other studies. ${ }^{28}$ In addition, more than half of the participants stated that the potential participants need to be notified at least one month before the implementation of the program. So the design and implementation of codified programs based on the views of the audiences, together with the design and implementation 
of a scientific assessment of the needs of the beneficiaries and the experts in the training program can increase the motivation for participation and the active presence of nurses in CEP. Almost all nurses agreed that participation in training programs should be considered a work shift, which can be a motivator for their participation in such programs.

\section{Conclusions:}

Finally, it seems that awareness of the audience's views regarding CEP and their various aspects is very important. If the implementation of CEP is based on the needs and circumstances of the participants, this can lead to increased motivation of the participants and productivity of the programs. Improving the training of the nurses and the implementation of educational programs requires further study. In this regard, it is recommended that studies be conducted in order to evaluate and assess the effects of CEP on professional performance, productivity, and satisfaction levels of the people.

\section{Research limitations:}

The non-probability sampling method used and the lack of cooperation by all the nurses to participate in the study and thus a 30\% reduction in the study sample size are among the limitations of the present study.

\section{Conflict of interest: None.}

\section{References:}

1. Pourghane P, Emamy Sigaroudy AH2, Salary. Faculty Members' Experiences about Participating In Continuing Education Programs In 2016- 2017: a Qualitative Study.2018;10(1):10-20.

2. Solhi H, Cyrus A, Noroozi A, Sedighi I Continuing Medical Education: Traditional or Electronic.;J of Iraninan Resarch in Education.2011;3(1):11-16.

3. Mohajmmadi, M.A., Mohammadkhah, B. Continuous Medical Education of nurses working in hospitals of Ardebil. J. Ardabil Uni. Med. Sci. 2005;5(3):271-277.

4. Yost J, Ciliiska D, Dobbins M. Evaluating the impact of an intensive education workshop on evidence- informed decision making knowledge, skills and behaviors: a mixed methods study. BMC Med Educ 2014;17(13):14: 13.

5. Richards L, Potgieter E. Perceptions of registered nurses in four state health institutions on continuing formal education. Curationis 2010; 33 (2): 41-50.

6. Shakurnia, H., Basir, L. Reviewing dentists in the city of Ahvaz in continuing education programs in Ahvaz. J. Med. Sci., 2010;8(3):331-335.
7. Jadidi R, Fazeli M. The content matches the needs of subjects of continuing education training programs Radiology 2008. J.Arak Med. Sci. Uni. 2009;12(4):15-23.

8. Eslamian J, Moeini M, Soleimani M. Challenges in nursing continuing education: A qualitative study. Iranian Journal of Nursing and Midwifery Research 2015;20(3):378- 386.

9. Waddell D. Why nurse participate in continuing education? Contin. Edu. Nursing. 2014;24(2):52-55.

10. Ni C, Hua Y, Shao P, Wallen GR, Xu S, Li L. Continuing education among Chinese nurses: A general hospital- based study. Nurse Educ T oday 2014;34 (4):592-7.

11. Griscti O, Jacono J. Effectiveness of continuing education programs in nursing: literature review. Journal of Advanced Nursing 2006;55(4):449-456.

12. Zubair M, Atai M,Abdol maleki, C. The ongoing adaptation of educational programs to the needs of medical professionals from the perspective of improving. J. Gen. Pract. Kermanshah 2007;11(1):69-76.

13. Koosha A. Kazemizanjani N. Nourian A.A. Mousavinasab N. General Practitioners' Viewpoints about Continuous Medical Education Programs Strides in Development of Medical Education. J. Med. Edu. Devel. Center Kerman Uni. Med. Sci. 2010;7(1):70-74.

14. Shirazi M, Zainal VA, Alaeddin, F. General surgery training needs in continuing education programs Tehran University of Medical Sciences from the perspective of the participants. Iranian J. Med Edu. 2005;(11):29-33.

15. Olivieri JJ, Regala RP. Improving CME: using participant satisfaction measures to specify educational methods. J Contin Educ Health Prof.2013;33(2):146-7.

16. Ebadi, A., Vanaki, Z., Tahrir, B., Hekmatpour, D.,. Pathology continuing education programs in the medical community". Strides in Development of Medical Education. J. Med. Edu. Devel. Center Kerman Uni. Med. Sci. 2007;4(2):140-145.

17. Jalali, R., Abdolmaleki, P., Kahrizi, M. Perspective of nurses in continuing education programs to improve Kermanshah. J. Behbod 2006;10(28):67-75.

18. Mirshazadeh, N., Totonchi, M., Quality of Books, Questions and Teaching Method of Self-Learning in Continuing Medical Education: Comments participants self, Isfahan University of Medical Sciences. Iranian J. Med. Edu. 2008;17(1):136139.

19. Khoramirad A, Heydari A, Ahmari Tehran H. Comparison of Two Methods of Self-Learning (CD and manual) to educate physicians about reporting diseases. Iranian J. Med. Edu. 2011;11 (2):149-158. 
20. Keshmiri M, Vanaki Z, Memarian R. Effects of applying "The Participative Continuing Education Based on Competency Model" on quality of intensive nursing care in open heart surgery. Quarterly Journal of Nursing Management 2017;6(2):20- 30 .

21. Haghdoost A, Momtazmanesh N, Shoghi F, Mohagheghi M, Mehrolhassani M. Accreditation the Education Development Centers of Medical- Sciences Universities: Another Step toward Quality Improvement in Education. Iran J Public Health 2013;42 (Supple 1):134- 40

22. Ebrahimi Kooshkmahdi, S., Assadi, R. The Utilization of Web-based Continuing Medical Education Courses in Mashhad University of Medical Sciences and its Relationship with Course Characteristics. Iranian J. Med. Edu. 2012;12(2):74-83

23. Ruf, D., Berner, M.M., Kriston, L., Maier, I., Harter, M., 2008. General practitioners online: the condition are good, but use of the Internet for continuing medical education found to be poor". Z. Evid. Fortbild. Qual. Gessundhwes. 102(5):291-297.
24. Leifer, D.,. Do you have a plan? Nurs. Stand. 2002;16(41): 14-17.

25. Borji, A., Imani, M., Moradi, A.,. The study of general practitioners' views on the content of composed programs in Zahedan. Tabib-e Shargh J. Zahedan Uni. Med. Sci. Health Services 2004;2(6):145-151.

26. Vaezi AA, Vanaki Z, Ahmadi F. [Explaining the experiences of nurses about post-registration nursing education context: A qualitative study]. Journal of Medical Education and Development 2012;7(3):2-15.

27. Moattari M, Moghaddasi M, Mousavi Nasab M, Razavieh A [ The Effect of Clinical Education Workshop on Nursing and Midwifery Instructors' Effective Behaviors in Clinical Education]. Iranian Journal of Medical Education 2006;6(2):97-105.

28. Vahidshahi, K., Mahmoudi, M., Shahbaznezhad, L., Ghaffari Saravi, V. Basic medical perspective on the situation and motives of the participants in retraining programs and how to implement it. Iranian J. Med. Edu. 2008;7(2):161-167. 